\title{
Using the Engineering Grand Challenges to Foster Critical Thinking and Awareness of the Engineer's Role in the Global Community
}

\section{Dr. Angela Thompson P.E., University of Louisville}

Dr. Angela Thompson is an Assistant Professor in the Department of Engineering Fundamentals at the University of Louisville. Dr. Thompson received her PhD in Mechanical Engineering from the University of Louisville. Her research interests are in biomechanics and engineering education, particularly related to critical thinking instruction.

\section{Dr. Patricia A Ralston, University of Louisville}

Dr. Patricia A. S. Ralston is Professor and Chair of the Department of Engineering Fundamentals at the University of Louisville. She received her B.S., MEng, and $\mathrm{PhD}$ degrees in chemical engineering from the University of Louisville. Dr. Ralston teaches undergraduate engineering mathematics and is currently involved in educational research on the effective use of technology in engineering education, the incorporation of critical thinking in undergraduate engineering education, and retention of engineering students. She leads a research group whose goal is to foster active interdisciplinary research which investigates learning and motivation and whose findings will inform the development of evidence-based interventions to promote retention and student success in engineering. Her fields of technical expertise include process modeling, simulation, and process control. 


\title{
Using the Engineering Grand Challenges to Foster Critical Thinking and Awareness of the Engineer's Role in the Global Community
}

\begin{abstract}
Critical thinking is a key component in the Introduction to Engineering course at the University of Louisville. In past years, instructors provided explicit instruction in critical thinking using the Paul-Elder critical thinking framework to guide and help students reflect on their thinking. In Fall 2014, faculty sought to enhance and expand critical thinking instruction in the course by providing students with more meaningful opportunities to apply the framework. Several written assignments for this course were crafted around the Grand Challenges. The purpose of these assignments was two-fold. First, students would have meaningful opportunities to develop their critical thinking skills by analyzing current engineering issues. Second, it was hoped that students would gain an awareness of engineers' roles in the global community by exposure to the Grand Challenges.

Student written assignments were assessed for their demonstration of critical thinking ability and integration of the Paul-Elder framework. Individual assignments at the beginning and end of the semester were scored by two faculty raters using a holistic engineering rubric based on the PaulElder framework. The assessments did not provide evidence that critical thinking skills improved. However, results highlighted the complexity of measuring critical thinking ability and comparing differing assignments. Additionally, students were surveyed at the end of the semester to assess their perceptions of the assignments and course activities. Perceptions of the assignments' effect on developing critical thinking skills were mixed; however, a majority of students indicated that the assignments were successful in increasing their awareness of the impact of engineering decisions on community issues. Results of this study revealed the need for further instruction in critical thinking to achieve desired course outcomes and for improved assessment of student learning with regards to critical thinking.
\end{abstract}

\section{Introduction}

All first-year engineering students at the University of Louisville are required to take an Introduction to Engineering course. This is a large enrollment course (in the fall of 2014, there were approximately 630 students in 18 sections) taught by two faculty and four teaching assistants. Although only one credit hour, many topics are covered, including introductions to the different engineering disciplines, instruction in critical thinking, team building and communication, ethics, professionalism, and an introduction to engineering design.

Critical thinking instruction in particular, has been one area the instructors have aimed to improve and reinforce in each iteration of the course. Students in this course are provided explicit instruction in the Paul-Elder (PE) Critical Thinking framework (Figure 1). ${ }^{1}$ The PE framework was adopted by the University to improve critical thinking skills for all undergraduates across the curriculum. In addition to explicit instruction of the PE framework in the Introduction to Engineering course, the PE framework is an implicit part of many later courses in the engineering curriculum. The framework highlights that good critical thinking involves identifying the elements of one's reasoning and assessing the quality of that reasoning 
using standards. In past years, students applied the framework through analysis and evaluation of an engineering related article and were encouraged to use the framework in development of reports for a separate design project. ${ }^{2-4}$ However, student feedback indicated that the framework was still not well-understood or utilized. Additionally, difficulties were encountered assessing whether students' critical thinking abilities actually improved after instruction and course activities. In Fall 2014, faculty sought to enhance and expand critical thinking instruction in the course by providing students with more meaningful opportunities to apply the PE framework.

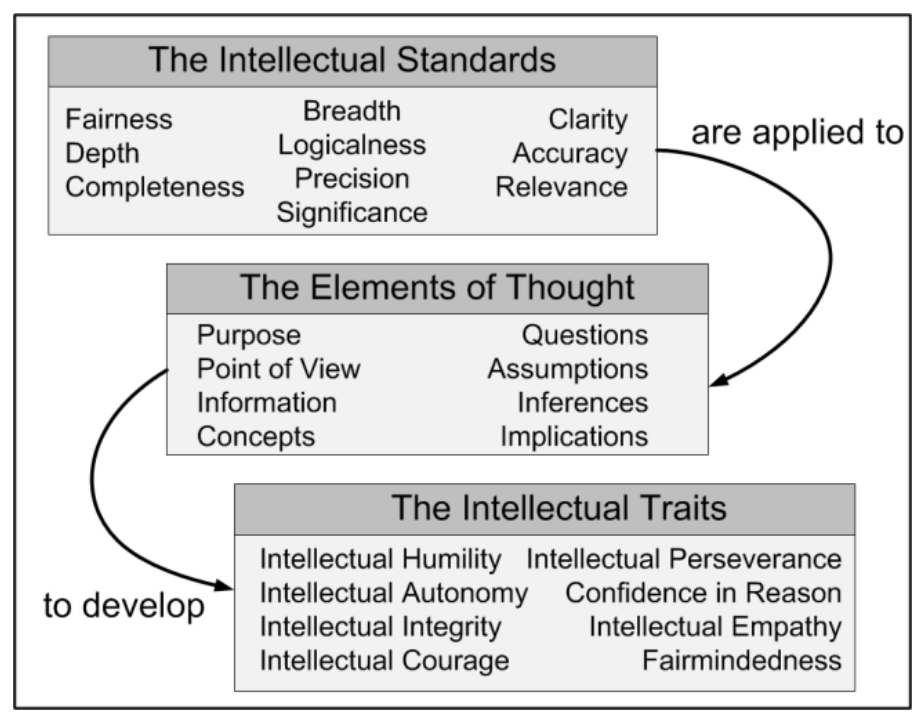

Figure 1. The Paul-Elder Framework of critical thinking. ${ }^{1}$

Previous studies have reported benefits of using the National Academy of Engineering's Grand Challenges in first-year courses to increase student interest and learning outcomes through exposure to real-world engineering applications. ${ }^{5-7}$ Huettel et al. developed a multi-stage framework that centered on the Engineering Grand Challenges in hopes that integration of meaningful real-world problems into the curriculum would improve student motivation and learning outcomes. ${ }^{5,6}$ The framework was comprised of six stages in which students were first introduced to the Grand Challenges from a broad, multidisciplinary perspective. Then students focused in on the specific, engineering aspects of the challenge, applying course content to a real-world problem inspired by the challenge, and finally reflected on their learning. This framework was implemented into three courses, an introductory engineering course and two upper level courses. The authors found that the overall class effectiveness (as reported by students) increased and student motivation increased in upper level courses after integration of the Grand Challenge framework. In another study, Corneal reported integration of the Grand Challenges into an Introduction to Engineering course as a semester-long project. ${ }^{7}$ Student teams investigated one of the Challenges through several course assignments and presented their findings at the end of the semester. Student perceptions of the course project on an end-ofsemester survey were positive with a majority of students indicating that working as a team was helpful, the project provided a good introduction to the engineering profession, they developed written and oral communication skills, and information gathering skills that would help them in their academic careers. 
Thus, several written assignments for this course were crafted around the Grand Challenges. The purpose of these assignments was two-fold. First, students would have opportunities to develop their critical thinking skills by analyzing current engineering issues. Second, it was hoped that students would gain an awareness of engineers' roles in the global community by exposure to the Grand Challenges.

\section{Methods}

Early in the semester, students were provided a brief introduction to the Engineering Grand Challenges (Table 1). ${ }^{8}$ Then students worked in teams of 4-5 to explore one of the Challenges more deeply and share their findings with the class. Over the course of the semester, students had three writing assignments relating to the Grand Challenges. For each of these assignments, students were evaluated on their demonstration of critical thinking. The first assignment was a short written reflection (1-2 paragraphs) in which students were to imagine they were given a large sum of money to form and lead a research team of engineers that would work towards addressing one of the Grand Challenges. Students were instructed to describe which challenge they would choose and justify their decision. This reflection was assigned prior to any instruction in the PE critical thinking framework. The second assignment, given after explicit instruction in critical thinking, was a team report on their selected Grand Challenge. Teams were specifically instructed to "analyze" their challenge using the PE framework as a guide, to gain a deeper understanding of the issues surrounding that particular challenge and develop their reports. Lastly, near the end of the semester, students were assigned a second individual reflection in which they were to consider the ethical issues surrounding one of the Grand Challenges.

\begin{tabular}{|l|}
\hline The National Academy of Engineering's Grand Challenges \\
\hline 1. Make solar energy economical \\
2. Provide energy from fusion \\
3. Develop carbon sequestration methods \\
4. Manage the nitrogen cycle \\
5. Provide access to clean water \\
6. Restore and improve urban infrastructure \\
7. Advance health informatics \\
8. Engineer better medicines \\
9. Reverse-engineer the brain \\
10. Prevent nuclear terror \\
11. Secure cyberspace \\
12. Enhance virtual reality \\
13. Advance personalized learning \\
14. Engineer the tools of scientific discovery \\
Table 1. The National Academy of Engineering's Grand Challenges
\end{tabular}

Three methods of assessment were used to evaluate the impact of the Grand Challenge assignments in achieving two learning outcomes: (1) students are able to explain the structure of the PE framework and apply the framework when solving problems, (2) students are aware of community issues within the engineering discipline. First, team reports on the Grand Challenges were assessed for the students' understanding and appropriate application of the Paul-Elder critical thinking framework. Second, for a subset of students $(n=107)$, individual reflections were 
evaluated against a holistic rubric based on the Paul-Elder framework to assess critical thinking ability. ${ }^{9}$ The rubric assesses critical thinking on a four point scale (Figure 2), with a score of four demonstrating the highest level of critical thinking. Each reflection was rated by two faculty. One rater was the primary instructor for the course; the second rater was not directly involved with the course but was involved in rubric development and had experience applying the rubric to rate student written assignments for a separate study. The student assignments were coded and all identifiers were removed before review by the second (non-instructor) faculty rater. Intraclass correlation coefficients were calculated to assess the reliability of the critical thinking rubric. Additionally, reflections at the beginning and end of the semester were compared to assess whether individual students' critical thinking abilities improved over the course of the semester. A Wilcoxin signed ranks test for paired samples was performed to determine if there were differences in critical thinking ratings at the beginning and end of the semester (statistical significance set at $\mathrm{p} \leq 0.05$ ). The third method of assessment was an anonymous survey provided at the end of the semester to assess students' perceptions of the assignments and critical thinking skill development.

Consistently does all or most of the following:

\begin{tabular}{|l|l|}
\hline & $\begin{array}{l}\text { Clearly identifies the purpose including all complexities of relevant questions. } \\
\text { Accurate, complete information that is supported by relevant evidence. } \\
\text { Complete, fair presentation of all relevant assumptions and points of view. } \\
\text { Clearly articulates significant, logical implications and consequences based on relevant } \\
\text { evidence. }\end{array}$ \\
\hline 2 & $\begin{array}{l}\text { Clearly identifies the purpose including some complexities of relevant questions. } \\
\text { Accurate, mostly complete information that is supported by evidence. } \\
\text { Complete, fair presentation of some relevant assumptions and points of view. } \\
\text { Clearly articulates some implications and consequences based on evidence. }\end{array}$ \\
\hline $\begin{array}{l}\text { Identifies the purpose including irrelevant and/or insufficient questions. } \\
\text { Accurate but incomplete information that is not supported by evidence. } \\
\text { Simplistic presentation that ignores relevant assumptions and points of view. } \\
\text { Articulates insignificant or illogical implications and consequences that are not } \\
\text { supported by evidence. }\end{array}$ \\
\hline $\begin{array}{l}\text { Unclear purpose that does not include questions. } \\
\text { Inaccurate, incomplete information that is not supported by evidence. } \\
\text { Incomplete presentation that ignores relevant assumptions and points of view. } \\
\text { Fails to recognize or generates invalid implications and consequences based on } \\
\text { irrelevant evidence. }\end{array}$ \\
\hline
\end{tabular}

Figure 2. Holistic rubric used to evaluate critical thinking ability. ${ }^{9}$

\section{Results}

Team reports on the Grand Challenges were reviewed for the students' demonstration of critical thinking using the PE framework. Specifically, reports were graded on the students' integration 
and understanding of the PE elements of thought (Figure 1). Instructor impressions after reviewing the reports were that students were generally able to integrate the elements into their reports clearly. Specifically, purpose and relevant questions were logical and clearly stated. However, differing points of view and implications beyond the most obvious (e.g. people need clean water to live, thus providing access to clean water would prevent many people from sickness and death) were often lacking. Additionally, students struggled with identifying underlying assumptions and supporting claims with evidence despite being encouraged to research the challenges and provide references in their reports.

Results of the critical thinking ratings using the holistic rubric on student reflections are shown in Figure 3. Faculty rated initial reflection assignments for 107 students (3 of 18 total course sections) and 95 end of semester reflections. Twelve students did not complete the final assignment. Reliability measures indicate reasonable agreement between the two raters using the rubric (intra-class correlation coefficients of 0.44 and 0.60 for the initial and final reflections, respectively). Additionally, the two raters had exact agreement on 50\% $(n=102)$ of all reflections and only differed by more than 1 point on $3 \%(n=6)$. Mean critical thinking ratings for the end of semester assignment were significantly lower than those at the beginning of the semester $(\mathrm{p}=0.014)$. These results indicate that as a whole, students demonstrated a lower quality critical thinking at the end of the semester than they did prior to any instruction in critical thinking and the PE framework.

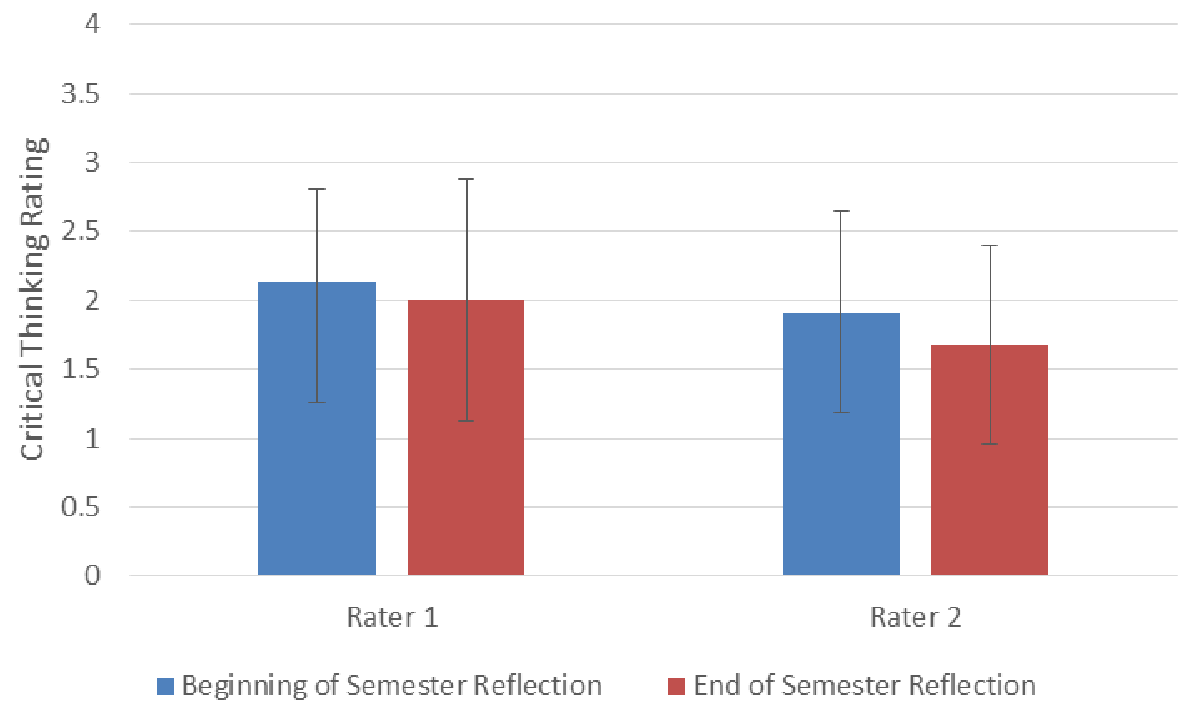

Figure 3. Mean and standard deviations of critical thinking ratings using holistic rubric for individual student reflections at beginning of semester (first) and end of semester (second).

Four survey questions (Figure 4) were provided to students to assess perceptions of the effectiveness of course activities on development of their critical thinking skills (questions 1-2) and their awareness of community issues within the engineering discipline (questions 3-4). Roughly a third of the students felt their critical thinking skills improved through knowledge of the Paul-Elder framework (34\% agree or strongly agree) and through opportunities (course activities and assignments) to apply the framework (37\% agree or strongly agree).

Approximately $29 \%$ of students felt knowledge and opportunities to apply the framework did not 
improve their critical thinking skills. A majority of students (63\%) felt that the Grand Challenges assignments made them more aware of the engineer's role in addressing community issues and an even greater percentage (83\%) agreed that awareness of community issues is important for practicing engineers.

1. My knowledge of the Paul-Elder critical thinking framework in ENGR 100 has improved my critical thinking skills

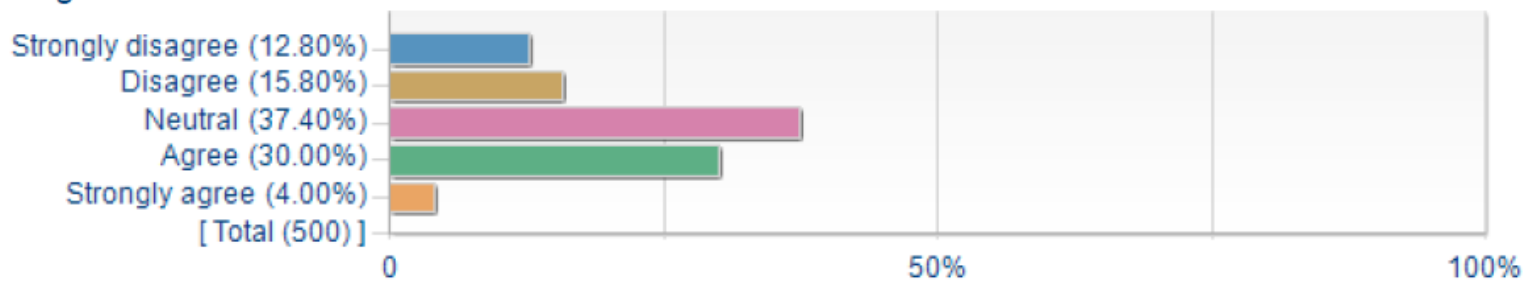

2. The opportunities to apply the Paul-Elder critical thinking framework in ENGR 100 have improved my critical thinking skills

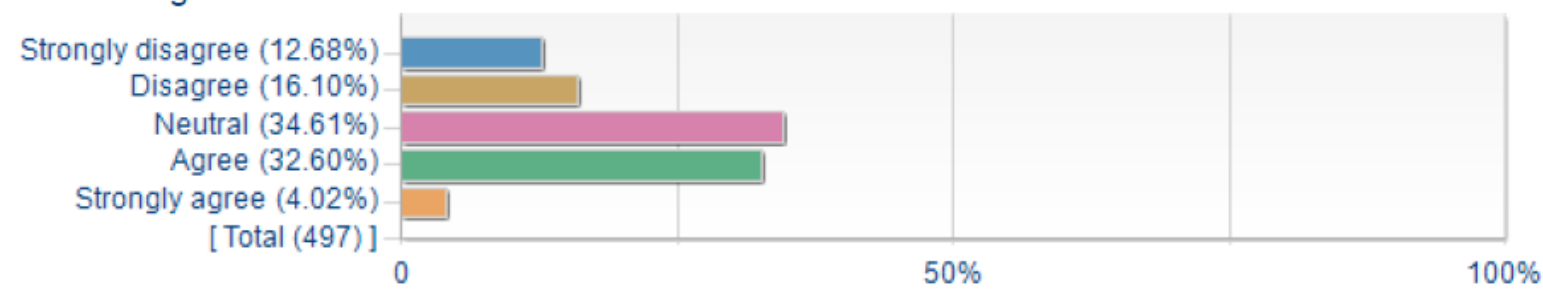

3. The class assignments related to the Engineering Grand Challenges Project in ENGR 100 have made me more aware that engineering decisions can affect community issues

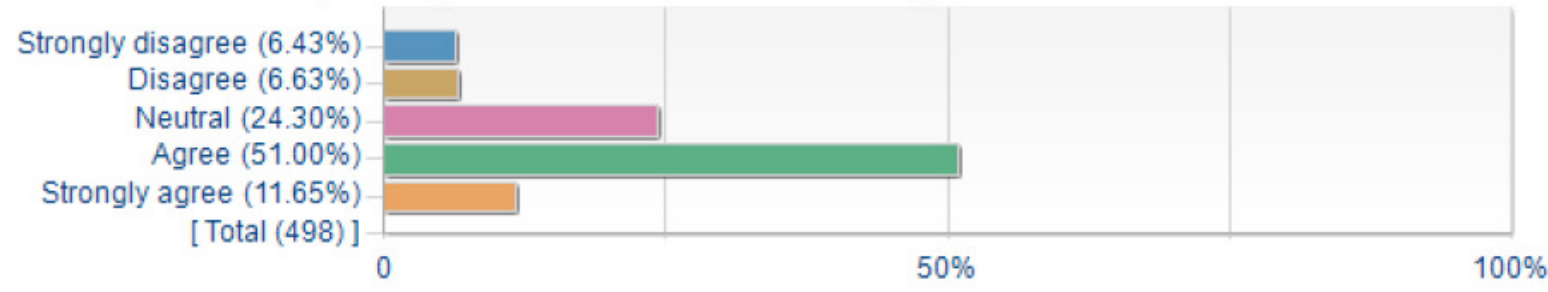

4. It is important for professional (practicing) engineers to be aware of community issues

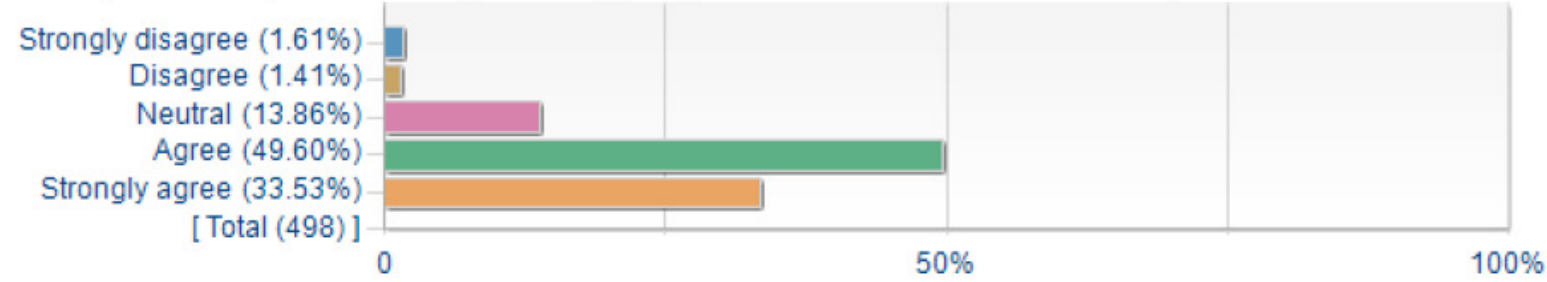

Figure 4. Results of end of semester survey provided to students.

\section{Discussion}

Results indicating the overall effectiveness of the Grand Challenge assignments on fostering critical thinking in the Introduction to Engineering course are mixed. Critical thinking assessments using a holistic rubric indicate that critical thinking skills did not improve (as demonstrated on two independent reflection assignments) and instructor impressions of the 
assignments suggest there is much room for improvement. About one-third of the students felt the assignments and instruction in the PE framework helped them to develop critical thinking skills. Though these results are disappointing, there are many limitations in the assessment method and perhaps most importantly, this study highlighted many areas in which students need additional instruction which will provide directions for future improvement.

The reliability of the holistic critical thinking rubric was reasonable and consistent with previous results. A previous study using the same rubric reported intraclass correlation coefficients ranging from 0.94 to -0.412 for several different pairs of raters scoring 176 written artifacts. ${ }^{9}$ However, several challenges were noted in scoring the student reflections as a part of this study. First, reflections may have been scored differently by the two raters due to different interpretations of the assignment and bias. Reflections rated by the faculty who was an instructor for the course scored higher on average, possibly due to bias as names were not blinded. Additionally, expectations of student effort in composing the assignment may have differed between the two raters. For example, simply calling the assignment a "reflection" may have resulted in students interpreting the assignment as simply writing what comes to mind, rather than well-composed thinking, which in turn may have affected faculty ratings. It is also likely that expectations of students' critical thinking ability were higher for the second assignment (both raters were aware that this assignment occurred at the end of semester after explicit instruction and activities related to critical thinking) resulting in lower scores. Second, it was difficult to score the reflections using the rubric due to the short length of the assignment (1-2 paragraphs). This length may have prevented students from thinking more deeply about the content.

In addition to the challenges of rating assignments using the critical thinking rubric, there are limitations in drawing comparisons between critical thinking scores on two different assignments. The lower scores at end of the semester do not necessarily indicate that the students' critical thinking abilities worsened. Rather differences could be due to the difficulty or timing of the assignments. In the first reflection assignment, students were asked to consider which Grand Challenge interested them most or they found most important - for which justification could be based on their personal experience alone. The second reflection assignment required students to think more deeply about ethical implications and issues that would need to be considered in addressing one of the Grand Challenges. Though students were provided separate instruction on ethics in class, this assignment likely required further investigation and research by the students outside of class to answer fully. Additionally, both assignments were a small portion of their course grade (approximately 5\%) and it is possible that the students placed less value, and thus less effort, on the reflection at the end of the semester (when they were also concerned about end-of-semester projects and finals in other classes).

Survey results indicate that approximately one-third of students found the PE framework and related assignments helped improve their critical thinking skills, though almost an equal percentage (29\%) felt their critical thinking skills did not improve. These results are similar to those from past efforts to integrate the PE framework into the course and develop critical thinking skills - student perceptions of the PE framework and critical thinking development are mixed. ${ }^{410}$ It was clear from reviewing the team reports on the Grand Challenges that students still struggle with some of the concepts, and though time is spent in class evaluating others' writing, students have difficulty using the framework as a guide for their own writing. Future 
efforts should be made to demonstrate to the students how the framework can be used to enhance their own thinking and decision-making.

The second goal of the Grand Challenge related assignments was that students would gain an awareness of engineers' roles in the global community. Though no direct assessment of student awareness was conducted, instructor impressions and survey results were positive. Nearly twothirds of the students felt the Grand Challenge assignments made them more aware of the impact of engineers on community issues. An even greater number $(83 \%)$ of students recognized the importance of this awareness for professional engineers. Exposure to the Grand Challenges may have benefited this population of first-year students not only by providing real-world examples of engineering problems, but also by showing the impact that engineers can have on the global community.

\section{Conclusions and Future Directions}

Three written assignments related to the National Academy of Engineering's Grand Challenges were implemented into an Introduction to Engineering course for first-year students. The assignments were intended to foster critical thinking, a significant learning outcome for the course, and provide real-world engineering examples that would develop the students' awareness of the engineer's role in addressing community issues. Assessments of students' critical thinking ability on an individual basis at the beginning and end of the semester did not provide evidence that critical thinking skills improved. However, the results may be misrepresentative due to the complexity of comparing differing assignments. Though student perceptions of the assignments' effect on developing critical thinking skills were mixed, a majority of students indicated that the assignments were successful in increasing their awareness of community issues.

Despite mixed results, faculty recognized value in the addition of the Grand Challenge-based assignments on student learning outcomes. Thus, the assignments will be retained for future semesters but refined to enhance their effectiveness with respect to students' critical thinking development. Efforts should be made to assist students in recognizing the value in using the PE framework to improve and reflect on their own thinking. One possible improvement is giving students opportunities to revise their assignments after feedback, thus encouraging them to refine their own thinking. Additionally, students will be given opportunities in class to evaluate their own writing and that of their peers using the PE framework. Like revision, it is hoped that this activity will enable students to reflect on their own thinking and identify areas for improvement. Further, through both revision and self-evaluation, students may see improvements in their critical thinking skills over time more clearly.

\section{References}

1. Paul, Niewoehner, and Elder. (2006). The Thinkers Guide to Engineering Reasoning. Foundation for Critical Thinking.

2. Lewis, Hieb, Wheatley. (2009). Explicit Teaching of Critical Thinking in "Introduction to Engineering". ASEE Annual Conference. Austin, TX. 
3. Lewis, Hieb, Wheatley. (2010). Introducing Critical Thinking to Freshman Engineering Students. ASEE Annual Conference. Louisville, KY.

4. Thompson A. (2014). Peer Assessment of Design Reports in a First-Year Introduction to Engineering Course. ASEE Annual Conference. Indianapolis, IN.

5. Huettel, Gustafson, Nadeau, Schaad, Barger, Linnenbrink-Garcia. (2013). A Grand Challenge-Based Framework for Contextual Learning in Engineering. ASEE Annual Conference. Atlanta, GA.

6. Huettel, Gustafson, Nadeau, Schaad, Barger, Linnenbrink-Garcia. (2014). Evidence for the Effectiveness of a Grand Challenge-Based Framework for Contextual Learning. ASEE Annual Conference. Indianapolis, IN.

7. Corneal, Lindsay. (2014). Use of the National Academy of Engineering's Grand Challenges for Engineering as a semester-long project for an Introduction to Engineering course. ASEE Annual Conference. Indianapolis, IN.

8. NAE Grand Challenges for Engineering. (2012) National Academy of Engineering, Washington, DC. http://www.engineeringchallenges.org/. accessed Feb. 1, 2015.

9. Ralston, P and Bays, C. (2010). Refining a Critical Thinking Rubric for Engineering. ASEE Annual Conference. Louisville, KY.

10. Thompson, Ralston, Hieb (2012). Engaging Freshmen Engineers using the Paul-Elder Framework for Critical Thinking. ASEE Annual Conference. San Antonio, TX. 